\title{
Surface Modification of Polypropylene Molded Sheets by Means of Surface-Initiated ATRP of Methacrylates
}

\author{
By Tomoaki MatSUGI,${ }^{1, *}$ Junji SAITO,${ }^{1}$ Nobuo KAWAHARA,${ }^{1}$ Shingo Matsuo,${ }^{1}$ Hideyuki KaneKo, ${ }^{1}$ \\ Norio KASHIWA, ${ }^{1}$ Motoyasu KOBAYASHI, ${ }^{2}$ and Atsushi TAKAHARA ${ }^{2, *}$
}

Structurally well-defined polypropylene-macroinitiator (PP-MI) sheets promoted the surface-initiated atom transfer radical polymerization (ATRP) of methyl methacrylate (MMA) under the mild conditions. There was no change in visual appearance on the surface during the surface-initiated ATRP. Surface analyses by attenuated total reflection infrared (ATR-IR) spectra and X-ray photoelectron spectra clearly showed the presence of PMMA segment grafting from the initiation sites on the surface of PP-MI sheet. Moreover, a uniform layer $(c a .60 \mathrm{~nm})$ consisted of the grafted PMMA brush was directly observed by cross-sectional surface image of transmission electron micrograph measurement. The thicknesses of PMMA layers were linearly increased corresponding with the molecular weight of the grafted PMMA, and the graft densities of PMMA were estimated to be 0.36 chains $/ \mathrm{nm}^{2}$. A dynamic friction test of the resulting PMMA-grafted PP sheet was carried out by sliding a stainless ball probe to reveal higher wear resistance to abrasion characteristics compared to a PMMA-coated PP sheet. Utilizing this grafting technique, highly wettable poly(2-methacryloyloxyethyltrimethyl ammonium chloride) (PMTAC) was also successfully grafted from the PP-MI sheet. The contact angle against distilled water reached to $8^{\circ}$, representing that the surface wettability was drastically improved by grafting highly wettable polymer chains. In addition, the sheet showed a high antibacterial property against Escherichia coli and Staphylococcus aureus.

KEY WORDS: ATRP / Polypropylene / Sheet / Surface-Initiated Polymerization / Wettability / Antibacterial Property /

Polyolefins are the most widely used commercial polymers, and their worldwide production has grown to more than 100 million tons per year. ${ }^{1}$ Their excellent properties such as high mechanical strength and flexibility, chemical stability and good corrosion-resistance, along with their high processability, has led to their current widespread use for molding materials producing films and sheets. In particular, the improvement of the surface properties for polyolefin moldings is one of the important issues to be resolved in order to broaden applicationability. A lot of modification approaches of the polyolefin moldings' surface have been demonstrated involving chemical treatment or physical treatment. ${ }^{2-5}$ As the modification by grafting of small polar molecules, the corona discharge treatment and plasma treatment have conventionally been applied to improve the surface wettability and paintability for polyolefin moldings by the oxidation reaction forming carbonyl, hydroxy and carboxylate functional groups on the polyolefin surface. The modification by grafting polymeric segment was also demonstrated. For instance, Moro et al. has reported on grafting highly wettable poly(methacrylate) onto the surface of ultra-high molecular weight polyethylene grown from radical species generated by ultraviolet irradiation. ${ }^{6}$ The resulting polyethylene showed not only a low friction coefficient in water but also biologically a high affinity, which is promising for artificial joint development. However, it has been reported that their treatments accompanied unfavorable chain cleavages of the polymer, and conveyed their surface to hydrophobic with the lapse of time as a result of migration and interpenetration of functional groups to reduce surface energy. ${ }^{7,8}$ Therefore, the grafted molecules (or polymer) were structurally less definite and immobilized with low graft density on the surface.

Contrasted to these modification techniques, some new approaches using a controlled/living radical polymerization system have been reported for the last decade. In particular, atom transfer radical polymerization (ATRP) has been applied to surface-initiated polymerization to produce well-controlled and high-density grafted polymer brush structure on the surface of hard materials such as metal, silicon substrate, and silica nano particles. ${ }^{9,10}$ However, surface-initiated ATRP from polyolefin surfaces has not been reported so much because of the difficulty in creation of the suitable initiating site for ATRP on the polyolefin surface. For instance, Shingh et al. grafted poly( $N$-isopropylacrylamide) (PNIPAM) from a partially-brominated polypropylene (PP) sheet by surface-initiated ATRP to reduce its surface water contact angle from $95^{\circ}$ to $45^{\circ} . .^{11}$ Yamamoto et al. also reported nickel-mediated ATRP of methyl methacrylate (MMA) from the surface of high density polyethylene to produce a PMMA-grafted polyethylene sheet. ${ }^{12,13}$ However, the characterization of brush layer is not sufficiently understood, especially in molecular weight of brush, graft density, chemical structure of initiating site on the polyolefin surface, and the relationship between the grafted structure and the chemical and physical properties.

\footnotetext{
${ }^{1}$ Research Center, Mitsui Chemicals, Inc., 580-32 Nagaura, Sodegaura 299-0265, Japan

${ }^{2}$ Institute for Materials Chemistry and Engineering, Kyushu University, 744 Motooka Nishi-ku, Fukuoka 819-0395, Japan

*To whom correspondence should be addressed ( ${ }^{1}$ Tel: +81-438-64-2319, Fax: +81-438-64-2370, E-mail: tomoaki.matsugi@mitsui-chem.co.jp, ${ }^{2}$ Tel: +81-92-802-2517, Fax: +81-92-802-2518, E-mail: takahara@cstf.kyushu-u.ac.jp).
} 

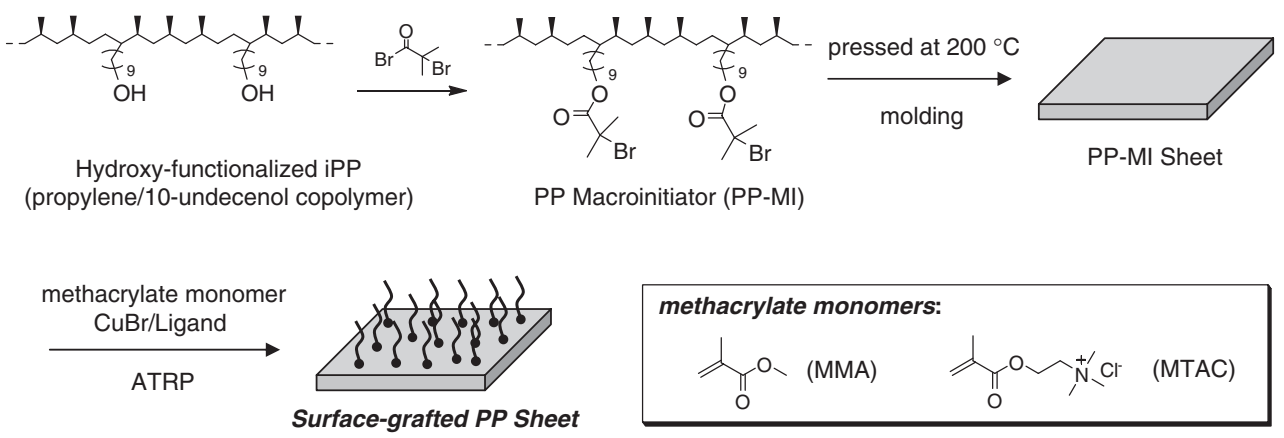

Scheme 1.

Recently, we prepared block ${ }^{14,15}$ and graft ${ }^{15-17}$ copolymers consisting of polyolefin and poly(methacrylate) by ATRP using an originally-developed polyolefin macroinitiator (PO-MI), which have a well-defined chemical structure prepared through the controlled metallocene-catalyzed copolymerization of $\alpha$ olefin and $\omega$-hydroxy- $\alpha$-olefins. ${ }^{18,19}$ PO-MIs having a various range of elasticity and thermal properties are available by controlling the molecular weight and chemical structure of $\alpha$-olefin monomers. In addition, the number of the initiation site and position in PO-MI chain are also precisely controlled.

We report here the synthesis of poly(methacrylate)s-grafted PP sheets using structurally well-defined polypropylene-macroinitiator (PP-MI) as shown in Scheme 1, and analyzed their surface structures. Then, the mechanical property, wettability and antibacterial properties of the surface-grafted sheets are investigated from the viewpoint of their application to novel valuable surface modification of polyolefins.

\section{EXPERIMENTAL}

\section{General Procedures and Materials}

All manipulations of air- and/or moisture-sensitive materials were handled under a dry nitrogen atmosphere using in a conventional nitrogen-filled glovebox. Dried solvents (toluene, 2-butanone, methanol and ethanol) were purchased from Wako Pure Chemical Industries, Ltd., and used after removal of oxygen by $\mathrm{N}_{2}$ bubbling for $1 \mathrm{~h}$. MMA monomer (Wako Pure Chemical Industries, Ltd.) was distilled over calcium hydride under reduced pressure. 2-Methacryloyloxyethyltrimethyl ammonium chloride (MTAC) (ca. 80\% in water) (stabilized with MEHQ) was purchased from Tokyo Chemical Industry Co. Ltd., and used without further purification. Copper(I) bromide $(\mathrm{CuBr}), N, N, N^{\prime}, N^{\prime \prime}, N^{\prime \prime}$-pentamethyldiethylenetriamine (PMDETA), ethyl 2-bromoisobutyrate (EBiB) and 4,4'-dimethyl-2,2'-bipyridyl were purchased from Wako Pure Chemical Industries, Ltd., and used without further purification. All other chemicals were obtained commercially and used as received.

\section{Preparation of the PP-MI Sheet}

$50 \mathrm{~g}$ of hydroxy-functionalized polypropylene powders prepared following the similar procedure described in the previous $\operatorname{paper}^{17}$ (propylene/10-undecen-1-ol copolymer containing $1.7 \mathrm{mmol}$ of hydroxy groups) was placed under nitrogen in a $1000 \mathrm{~mL}$ glass flask equipped with a mechanical stirrer and a thermometer, and diluted with $500 \mathrm{~mL}$ of dried toluene to give a slurry solution. 2-Bromoisobutyryl bromide $(8.5 \mathrm{mmol})$ was slowly added to the polymer solution at $80^{\circ} \mathrm{C}$ and was reacted for $2 \mathrm{~h}$. The reaction mixture was cooled to $40^{\circ} \mathrm{C}$ and poured into methanol (2L). The resulting polymer was collected by filtration, washed with methanol $(200 \mathrm{~mL} \times 2$ times), and dried at $80^{\circ} \mathrm{C}$ under vacuum. Then, PP multifunctional macroinitiator (PP-MI) was obtained as white powder in a quantitative yield. The number-average molecular weight $\left(M_{\mathrm{n}}\right)$ and molecular weight distribution $\left(M_{\mathrm{w}} / M_{\mathrm{n}}\right)$ was 56400 $\mathrm{g} / \mathrm{mol}$ and 1.9 , respectively. The composition of $\alpha$-bromoisobutyrate was determined by ${ }^{1} \mathrm{H}$ NMR in $o$-dichlorobenzene- $d_{4}$ at $120{ }^{\circ} \mathrm{C}$ to be $0.034 \mathrm{mmol}$ in a gram-polymer. The resulting PP-MI powder was molded into sheets with 0.5 and $1.0 \mathrm{~mm}$ of thickness by compression molding with pre-heating at $200^{\circ} \mathrm{C}$ for $5 \mathrm{~min}$, press process under $5.0 \mathrm{MPa}$ at $200^{\circ} \mathrm{C}$ for $3 \mathrm{~min}$, cooling to $20^{\circ} \mathrm{C}$, and holding for $1 \mathrm{~min}$ at this temperature. The obtained PP-MI sheets were washed in acetone in an ultrasonic cleaner for $5 \mathrm{~min}$ to remove attached residues on the surface, and dried at $80^{\circ} \mathrm{C}$ under vacuum.

\section{Surface-Initiated ATRP of MMA from the PP-MI Sheet}

A typical ATRP of MMA was performed as follows: Three PP-MI sheets $(4 \mathrm{~cm} \times 4 \mathrm{~cm})$ were dipped in the mixture solution of 2-butanone $(70 \mathrm{~mL}), \mathrm{MMA}(210 \mathrm{mmol})$ and $\mathrm{EBiB}$ $(0.105 \mathrm{mmol})$ in a $100 \mathrm{~mL}$ separable flask equipped with a septum and a thermometer. The solution was bubbled with nitrogen for $30 \mathrm{~min}$ to remove oxygen. The other mixture of $\mathrm{CuBr}(0.35 \mathrm{mmol})$ and PMDETA $(0.70 \mathrm{mmol})$ diluted with 2butanone was injected to the flask using a gas tight syringe to start polymerization. About $15 \mathrm{~min}$ later, the resulting sheets were washed in $300 \mathrm{~mL}$ of acetone in an ultrasonic bath for 5 min 3 times, and dried at $80^{\circ} \mathrm{C}$ under vacuum. The reaction mixture containing PMMA free polymer generated from $\mathrm{EBiB}$ was flushed through a silica gel column to remove catalyst residue and poured into a large amount of methanol to precipitate the polymer. The resulting free polymer was collected by filtration, and dried at $80^{\circ} \mathrm{C}$ under vacuum to obtain as a white powder. 


\section{Surface-initiated ATRP of MTAC from PP-MI Sheet}

PP-MI with $17100 \mathrm{~g} / \mathrm{mol}$ of $M_{\mathrm{n}}, 1.7$ of $M_{\mathrm{w}} / M_{\mathrm{n}}$ and 0.14 $\mathrm{mmol} / \mathrm{g}$ of $\alpha$-bromoisobutyrate unit was prepared as abovementioned procedure, and molded into the sheet with the thickness of $1.0 \mathrm{~mm}$. Into a $100 \mathrm{~mL}$ separable flask equipped with a septum and a thermometer, the PP-MI sheet was placed with $222 \mathrm{~mL}$ of ethanol, MTAC $(125.1 \mathrm{~mL}$ of $80 \%$ water solution, $482 \mathrm{mmol}$ ), and $0.525 \mathrm{mmol}$ of $\mathrm{EBiB}$ in this order. After the resulting mixture was bubbled with argon for $30 \mathrm{~min}$, toluene solution of $\mathrm{CuBr}(0.88 \mathrm{mmol})$ and PMDETA $(1.75$ mmol) was injected into the flask using a gas tight syringe. The solution was heated to $60^{\circ} \mathrm{C}$ to polymerize for $4 \mathrm{~h}$. The resulting sheet was washed in $100 \mathrm{~mL}$ of methanol using an ultrasonic cleaner for $10 \mathrm{~min} 2$ times, and dried at $80^{\circ} \mathrm{C}$ under vacuum. The polymerization solution was poured into $300 \mathrm{~mL}$ of THF to precipitate unbounded PMTAC produced by EBiB. The free PMTAC was collected by filtration, and dried at $80^{\circ} \mathrm{C}$ under vacuum to obtain a white powder in $99 \%$ yield. The theoretical molecular weight was estimated as $187600 \mathrm{~g} / \mathrm{mol}$ $(\mathrm{DP}=903)$.

\section{Structural Analyses of the Polymers and the Sheets}

${ }^{1} \mathrm{H}$ NMR spectra of the hydroxy-functionalized PP and PPMI were recorded on a JEOL JNM GSX400 spectrometer $(400 \mathrm{MHz})$ using $o$-dichlorobenzene- $d_{4}$ at $120^{\circ} \mathrm{C}$. The $M_{\mathrm{n}}$ of the polymers containing PP segments was determined by high temperature size exclusion chromatography (HT-SEC) using a Waters alliance GPC2000 equipped with two TSKgel GMH6HT columns connecting to two TSKgel GMH6-HTL columns. Calibration curves were prepared by polypropylene standards. $o$-Dichlorobenzene $\left(145^{\circ} \mathrm{C}\right)$ was used as an eluent at a flow rate of $1.0 \mathrm{~mL} / \mathrm{min}$. The $M_{\mathrm{n}}$ of PMMA were determined by SEC R1704 (GL Sciences) through a STYLAGEL HR5E columns and two STYLAGEL HR6E columns using chloroform as an eluent at a flow rate of $0.8 \mathrm{~mL} / \mathrm{min}$ at $40^{\circ} \mathrm{C}$, and using standard PMMA calibration. Melting temperature $\left(T_{\mathrm{m}}\right)$ of the polymers was measured by using a Shimadzu DSC-60 differential scanning calorimeter (DSC), and was recorded during the heating to $200{ }^{\circ} \mathrm{C}$ from $30^{\circ} \mathrm{C}$ at the rate of $10{ }^{\circ} \mathrm{Cmin}^{-1}$. Attenuated total reflection infrared (ATR-IR) spectra of the sheet were measured using a Biorad FTS-6000 with a Ge prism. The spectra were taken at a resolution of $4 \mathrm{~cm}^{-1}$ after 32-scan accumulation for an acceptable signal/ noise ratio. X-Ray photoelectron spectroscopy (XPS) measurements were performed at a 35 degree take-off angle, and recorded on a Surface Science Instruments (SSI) SSX-100 $\mathrm{X}$-ray spectrometer equipped with a $\mathrm{AlK} \alpha$ X-ray source $(150 \mathrm{~W})$. After peak fitting of the $\mathrm{C}_{1 \mathrm{~s}}$ spectra, all the spectra were calibrated in reference to the unfunctionalized aliphatic $\mathrm{C}_{1 \mathrm{~s}}$ component at a binding energy of $285.0 \mathrm{eV}$. Transmission electron microscope (TEM) images were observed using HITACHI H-7000 transmission electron microscope at an acceleration voltage of $75 \mathrm{kV}$ and magnification range of 50000-200000 times. The ultra-thin ( $c a .100 \mathrm{~nm})$ sections of the grafted PP sheets for TEM measurement were prepared by cutting on a REICA Ultra-cut microtome equipped with a diamond knife at low temperature, and then stained with $\mathrm{RuO}_{4}$. The contact angles against distilled water were recorded with a drop shape analysis system CA-XE (Kyowa Interface Science Co., Ltd.). The friction coefficient on the grafted sheet and the coated sheet were recorded on a Tribostation Type32 (Shinto Scientific Co., Ltd.) by sliding a stainless ball $(\phi 10 \mathrm{~mm})$ on the sheet over a distance of $20 \mathrm{~mm}$ at a sliding velocity of $90 \mathrm{~mm} /$ min under loading of $0.49 \mathrm{~N}$. The friction force on the ball probe was transmitted to a stress gauge attached to a probe end, and was recorded automatically. The morphologies of the wear trace of the sheets were observed with a BXFM optical microscopy (Olympus). The antibacterial property of the sheet surface was tested versus Escherichia coli NBRC 3972 and Staphylococcus aureussubsp aureus NBRC 12732 at the Japan Food Research Laboratory.

\section{RESULTS AND DISCUSSIONS}

\section{Preparation of PMMA-grafted PP Sheets}

Three types of hydroxy-functionalized isotactic-polypropylenes having different content of hydroxy groups were prepared via the zirconium-metallocene catalyzed copolymerization of propylene with triisobutylaluminum-masked 10-undecen-1-ol according to a previously reported procedure. ${ }^{17}$ The hydroxy group was converted to $\alpha$-bromoisobutyrate moiety, wellknown as an initiation site for ATRP, by the reaction with an excess amount of 2-bromoisobutyryl bromide (Table I).

${ }^{1} \mathrm{H}$ NMR spectrum of the hydroxy-functionalized PP in Figure 1 showed characteristic triplet peaks at $3.40 \mathrm{ppm}$ due to the methylene protons of primary alcohol $\left(-\mathrm{CH}_{2} \mathrm{OH}\right)$ which was completely disappeared after the reaction. New triplet signals at $4.10 \mathrm{ppm}$ and singlet peak at $2.1 \mathrm{ppm}$ were observed in ${ }^{1} \mathrm{H}$ NMR spectrum of PP-MI (MI-1 in Table I) corresponding to the ester group $\left(-\mathrm{CH}_{2} \mathrm{OCOC}\left(\mathrm{CH}_{3}\right)_{2} \mathrm{Br}\right)$ and the $\alpha$-methyl group $\left(-\mathrm{CH}_{2} \mathrm{OCOC}\left(\mathrm{CH}_{3}\right)_{2} \mathrm{Br}\right)$, indicating that the esterification proceeded quantitatively. The content of $\alpha$-bromoisobutyrate moiety was determined by relative intensities between methylene proton signals of ester group at $4.10 \mathrm{ppm}$ and PP main chain at $0.9-1.7 \mathrm{ppm}$. The three kinds of PP-MIs with different $\mathrm{Br}$ contents $(0.034-0.103 \mathrm{mmol} / \mathrm{g}$-polymer) possessed sufficiently-high molecular weight $\left(M_{\mathrm{n}}=56400\right.$ 99500) and melting temperature $\left(T_{\mathrm{m}}\right)$ at $153-158^{\circ} \mathrm{C}$ for preparation of molded sheet (Table I). The PP-MI sheets (SMI-1, SMI-2, SMI-3) on the basis of thus obtained PP-MIs were prepared by compression molding method $\left(200^{\circ} \mathrm{C}, 3 \mathrm{~min}\right)$ with a fixed thickness of ca. $0.5 \mathrm{~mm}$.

Table I. Properties of polypropylene macroinitiators (PP-MIs)

\begin{tabular}{|c|c|c|c|c|c|}
\hline \multirow{2}{*}{ PP Sheet No. } & \multirow{2}{*}{$M_{\mathrm{n}}{ }^{\mathrm{a})}$} & \multirow{2}{*}{$M_{\mathrm{w}} / M_{\mathrm{n}}{ }^{\mathrm{a})}$} & \multicolumn{2}{|c|}{ Br content ${ }^{\text {b) }}$} & \multirow{2}{*}{$T_{\mathrm{m}}{ }^{\mathrm{c})},{ }^{\circ} \mathrm{C}$} \\
\hline & & & $\mathrm{mol} \%$ & $\mathrm{mmol} / \mathrm{g}$ & \\
\hline $\mathrm{Ml}-1$ & 56400 & 1.9 & 0.14 & 0.034 & 158 \\
\hline MI-2 & 69400 & 2.2 & 0.31 & 0.072 & 154 \\
\hline MI-3 & 99500 & 2.1 & 0.45 & 0.103 & 153 \\
\hline
\end{tabular}

a) $M_{w}$ and $M_{n}$ were determined by high-temperature SEC using polypropylene standard calibration. ${ }^{\text {b) }}$ Content of Bromo-terminals of $\mathrm{PP}-\mathrm{Br}$ was determined by ${ }^{1} \mathrm{H}$ NMR. ${ }^{\mathrm{c}} \mathrm{DSC}$ measurement. 

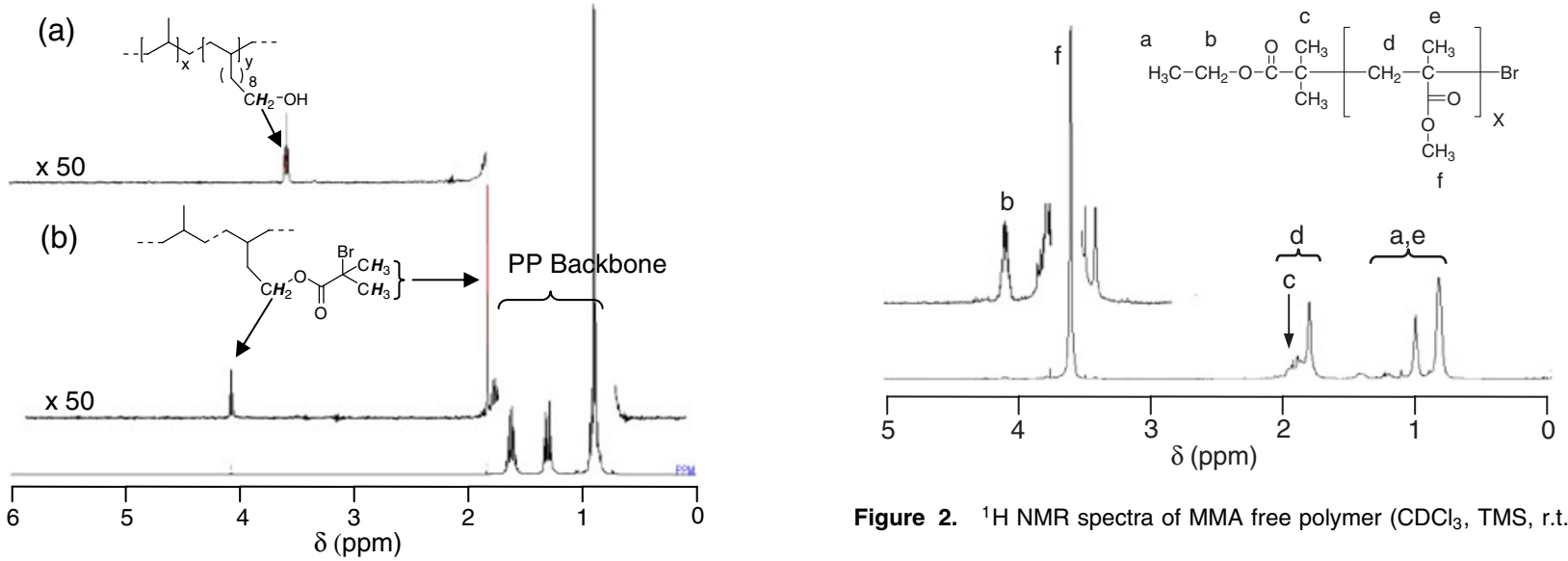

Figure 2. ${ }^{1} \mathrm{H}$ NMR spectra of MMA free polymer $\left(\mathrm{CDCl}_{3}, \mathrm{TMS}\right.$, r.t.).

Figure 1. ${ }^{1} \mathrm{H}$ NMR spectra of (a) hydroxy-functionalized PP containing $0.34 \mathrm{mmol} / \mathrm{g}$ of $\mathrm{OH}$-group and (b) PP-Ml $(400 \mathrm{MHz}$ in o-dichlorobenzene- $d_{4}$ at $120^{\circ} \mathrm{C}$ ).

Table II. Surface-initiated ATRP of MMA from PP-MI sheet in butanone at $27^{\circ} \mathrm{C}^{\mathrm{a}}$ )

\begin{tabular}{|c|c|c|c|c|c|c|}
\hline \multirow{2}{*}{ Entry } & \multirow{2}{*}{ PP-Ml sheet } & Feed molar ratio of reagents ${ }^{a)}$ & \multirow{2}{*}{ Time, $\mathrm{h}$} & \multirow{2}{*}{$M_{\mathrm{n}}{ }^{\mathrm{b})}$} & \multirow{2}{*}{$M_{\mathrm{w}} / M_{\mathrm{n}}{ }^{\mathrm{b})}$} & \multirow{2}{*}{$M_{\mathrm{n}, \mathrm{NMR}^{\mathrm{c}}}{ }^{\mathrm{c}}$} \\
\hline & & {$[\mathrm{CuBr}]_{0} /[\mathrm{PMDETA}]_{0} /[\mathrm{BiBB}]_{0} /[\mathrm{MMA}]_{0}$} & & & & \\
\hline 1 & SMI-1 & $1 / 2 / 0.30 / 600$ & 0.25 & 7200 & 1.55 & 7300 \\
\hline 2 & SMI-2 & $1 / 2 / 0.30 / 600$ & 0.25 & 7200 & 1.55 & 7300 \\
\hline 3 & SMI-3 & $1 / 2 / 0.30 / 600$ & 0.25 & 7200 & 1.55 & 7300 \\
\hline 4 & SMI-1 & $1 / 2 / 0.30 / 600$ & 1.0 & 20900 & 1.35 & 26000 \\
\hline 5 & SMI-2 & $1 / 2 / 0.30 / 600$ & 1.0 & 20900 & 1.35 & 26000 \\
\hline 6 & SMI-3 & $1 / 2 / 0.30 / 600$ & 1.0 & 20900 & 1.35 & 26000 \\
\hline 7 & SMI-1 & $1 / 2 / 0.30 / 600$ & 8.0 & 53700 & 1.55 & 55600 \\
\hline 8 & SMI-2 & $1 / 2 / 0.30 / 600$ & 8.0 & 53700 & 1.55 & 55600 \\
\hline 9 & SMI-3 & $1 / 2 / 0.30 / 600$ & 8.0 & 53700 & 1.55 & 55600 \\
\hline 10 & SMI-1 & $1 / 2 / 0.16 / 1200$ & 8.0 & 116000 & 1.85 & n.d. \\
\hline 11 & SMI-2 & $1 / 2 / 0.16 / 1200$ & 8.0 & 116000 & 1.85 & n.d. \\
\hline 12 & SMI-3 & $1 / 2 / 0.16 / 1200$ & 8.0 & 116000 & 1.85 & n.d. \\
\hline
\end{tabular}

a) $[\mathrm{CuBr}]_{0}=5.0 \mathrm{mM}$. ${ }^{\text {b) }} M_{\mathrm{w}}$ and $M_{\mathrm{n}}$ of PMMA generated from EBiB were determined by SEC. ${ }^{c}$ Determined by ${ }^{1} \mathrm{H}$ NMR.

Surface-initiated ATRP of MMA was carried out by dipping the sheets in MMA solution in the presence of $\mathrm{CuBr} / \mathrm{PMDETA}$ and ethyl 2-bromoisobutyrate. To avoid swelling and deformation of the PP-MI sheet, 2-butanone was used as a polar solvent and the polymerization was conducted at ambient temperature. The polymerization results are summarized in Table II.

Although the $M_{\mathrm{n}}$ of the grafted PMMA could not be directly determined, it is widely known that the $M_{\mathrm{n}}$ of the grafted polymer and the corresponding free polymer are the same values. $^{20-23}$ The $M_{\mathrm{n}}$ of unbound PMMA were estimated to be $7200-116000$ by SEC as shown in Table II. The $M_{\mathrm{n}}$ of PMMA increased with polymerization time and in initial concentration of the MMA. ${ }^{1} \mathrm{H}$ NMR spectrum of the free polymer was shown in Figure 2. Molecular weight of free PMMA was also estimated by the ratio of peak intensities between the methylene peaks $\left(\mathrm{CH}_{3} \mathrm{CH}_{2} \mathrm{OCO}-\right)$ of terminal ethyl group at 4.05-4.15 ppm and the methyl peak ( $\left.\mathrm{CH}_{3} \mathrm{OCO}-\right)$ of MMA at $3.6 \mathrm{ppm} .{ }^{24}$ The estimated values $\left(M_{\mathrm{n}, \mathrm{NMR}}\right.$ in Table II) corresponded well with the $M_{\mathrm{n}}$ determined by GPC, indicating that almost all of PMMA was grown from the ATRP-initiating sites.

\section{Characterization of PMMA-grafted on the PP Sheet}

Figure 3 showed the ATR-IR spectra of original PP-MI sheet, PMMA-grafted sheet, and PMMA film. PMMA-grafted PP sheet surface showed IR adsorption at $1733 \mathrm{~cm}^{-1}$ attributed to $\mathrm{C}=\mathrm{O}$ stretching vibration in ester group. The peak intensity at the region of $2800-3000 \mathrm{~cm}^{-1}$ due to $\mathrm{C}-\mathrm{H}$ stretching vibration of $\mathrm{PP}$ main chains reduced after the grafting reaction.

XPS measurement of PP-MI sheet and PMMA-grafted sheet were performed at a 35 degree take-off angle to determine the chemical species presenting at the surface. The $\mathrm{C}_{1 \mathrm{~s}}$ and $\mathrm{O}_{1 \mathrm{~s}}$ spectra and their corresponding fitting curves are shown in Figure 4 and Figure 5. In the case of PP-MI sheet, an intense $\mathrm{C}_{1 \mathrm{~s}}$ peak at a binding energy of $285.0 \mathrm{eV}$ occupied $95 \%$ of area. This main peak corresponds to aliphatic hydrocarbon of polypropylene main chain $\left(C_{\mathrm{a}}-\mathrm{C} / C_{\mathrm{a}}-\mathrm{H}\right)$. The weak shoulder peaks at $286.8,285.9$ and $289.2 \mathrm{eV}$ represents an ester-induced $\beta$-shifted carbon $\left(C_{\mathrm{b}}-\mathrm{COO}\right)$, the methylene ester $\left(C_{\mathrm{c}}-\mathrm{OCO}\right)$ and the carbonyl carbon $\left(C_{\mathrm{d}}=\mathrm{O}\right)$, respectively. The $\mathrm{O}_{1 \mathrm{~s}}$ spectra of the PP-MI sheet showed two peaks at 532.6 and $534.3 \mathrm{eV}$ corresponding to carbonyl oxygen $\left(O_{\mathrm{a}}=\mathrm{C}\right)$ and ester oxygen $\left(O_{\mathrm{b}}-\mathrm{CO}\right)$ (Figure $\left.5 \mathrm{a}\right)$. These results showed that $\alpha$-bromoiso- 


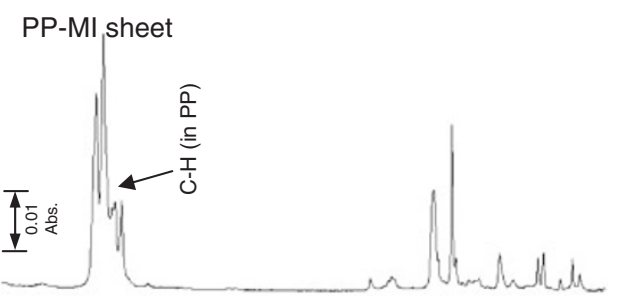

PMMA grafted on PP-MI sheet
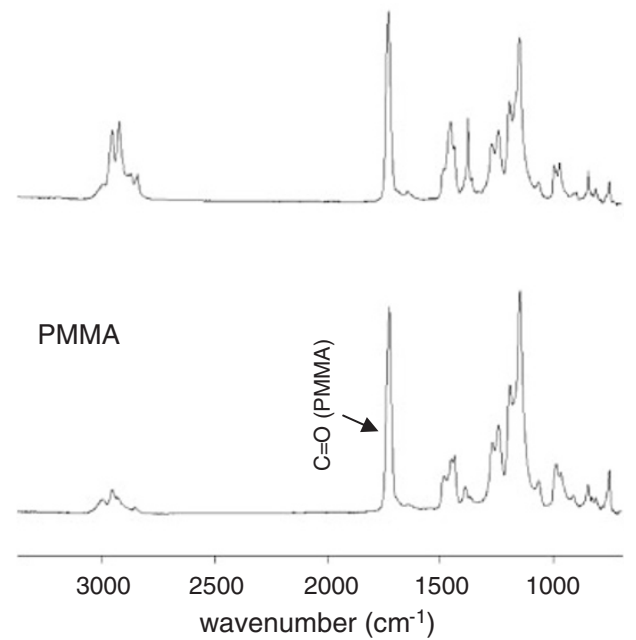

Figure 3. ATR-IR spectra of (a) PP-MI sheet (SMI-3) (b) PMMA-grafted sheet $\left(M_{\mathrm{n}}\right.$ of PMMA $\left.=116000\right)$ and $(\mathrm{c})$ PMMA (homo-polymer).

(a)

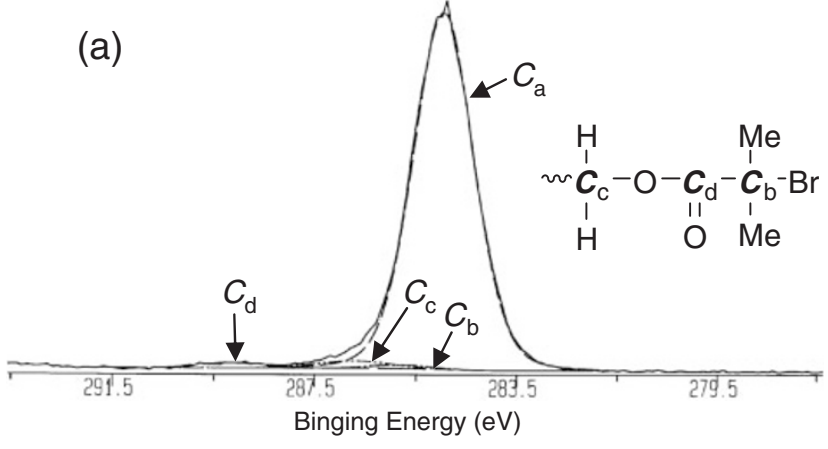

(b)

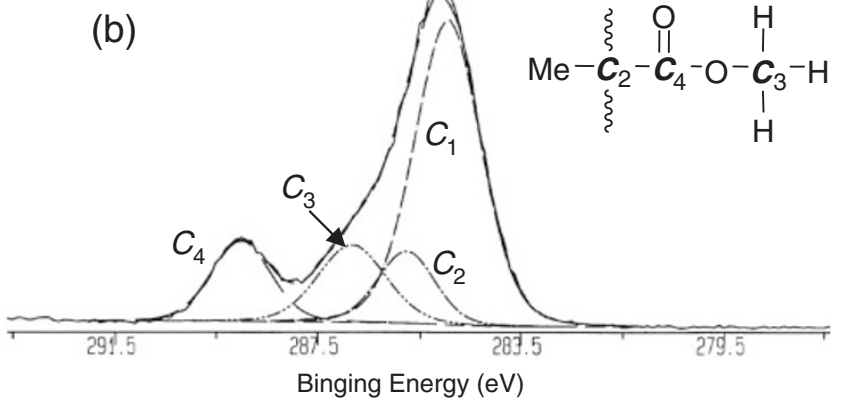

Figure 4. $\mathrm{C}_{1 \mathrm{~s}}$ XPS spectra of (a) PP-MI sheet (SMI-3) and (b) PMMAgrafted sheet $\left(M_{\mathrm{n}}\right.$ of PMMA $\left.=116000\right)$.
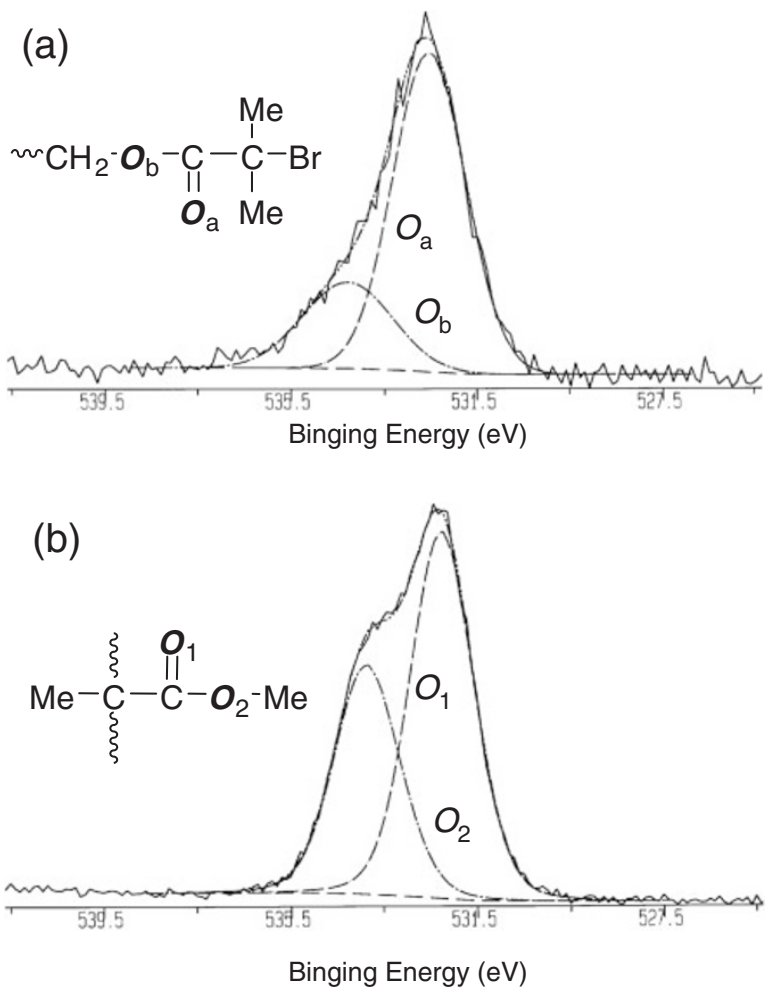

Figure 5. $\mathrm{O}_{1 \mathrm{~s}}$ XPS spectra of (a) PP-Ml sheet (SMI-3) and (b) PMMAgrafted sheet $\left(M_{n}\right.$ of PMMA $\left.=53700\right)$

butyrate groups, initiation sites for ATRP, were presented at the surface of PP-MI sheet. In the case of PMMA-grafted sheet, the $\mathrm{C}_{1 \mathrm{~s}}$ peaks also appeared around $285 \mathrm{eV}$ with a shoulder at the higher binding energy (Figure $4 \mathrm{~b}$ ). The $\mathrm{C}_{1 \mathrm{~s}}$ spectrum of PMMA-grafted sheet showed the four peaks at 285.0, 285.8, 286.9 and $289.1 \mathrm{eV}$ corresponding to $C_{1}-\mathrm{C} / C_{1}-\mathrm{H}, C_{2}-\mathrm{COO}$, $C_{3}$-OCO and $C_{4}=\mathrm{O}$, respectively. ${ }^{25}$ The peak intensities assigned to the ester group $\left(C_{2}, C_{3}\right.$ and $\left.C_{4}\right)$ were significantly larger than that of PP-MI sheet. The $\mathrm{O}_{1 \mathrm{~s}}$ spectra of PMMAgrafted sheet showed two peaks at 532.6 and $534.3 \mathrm{eV}$ corresponding to $\mathrm{O}_{1}=\mathrm{C}$ and $\mathrm{O}_{2}-\mathrm{CO}$, respectively (Figure 5b). From the results of above ATR-IR and XPS measurements, it was clearly indicated that PMMA-grafted layer was formed on the surface via ATRP of MMA. In addition, there was significant difference between PP-MI sheet and PMMA-grafted sheet in atomic ratio of carbon/oxygen. The $\mathrm{C} / \mathrm{O}$ atomic ratio of PP-MI sheet was estimated to be 13.8 . In contrast, the $\mathrm{C} / \mathrm{O}$ ratio of PMMA-grafted sheet was 2.9 , which is very close to 3.0 of the theoretical atomic ratio of bulk PMMA.

Structural features of PMMA on the surface of the PP-MI sheets were directly observed by TEM. Figure 6 shows a TEM image (cross-sectional view) of the PMMA-grafted surface of SMI-3 sheet with $M_{\mathrm{n} \text {,PMMA }}$ of $116000 \mathrm{~g} / \mathrm{mol}$. Dark gray area stained with $\mathrm{RuO}_{4}$ is PMMA layer, which is clearly observed with an extensively uniform thickness of $60.5 \pm 2.7 \mathrm{~nm}$ at the surface of the PP-MI sheet. A magnified image near the interface (inset image of Figure 6) showed that PP lamella was located in the PP matrix close to the interface between PP and 


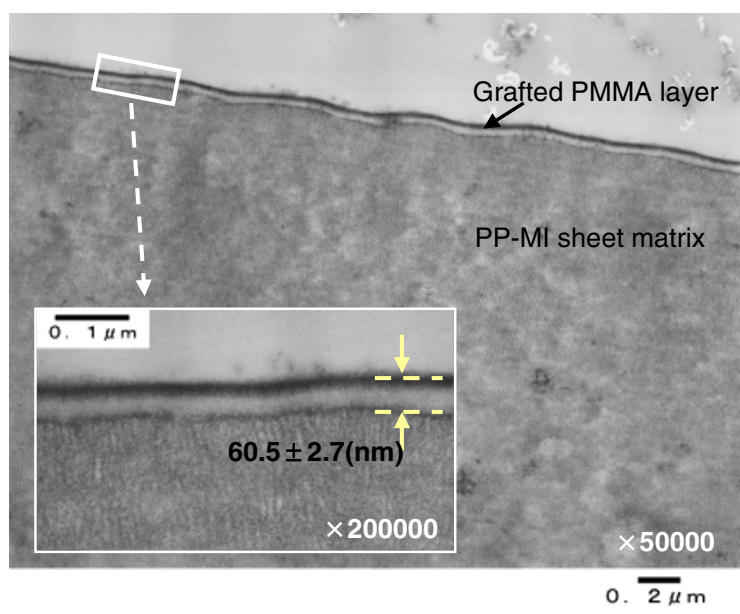

Figure 6. TEM image of the section nearby the surface of PMMA-grafted sheet at a magnification of $\times 50,000$ and $\times 200,000$ (inset image).

PMMA phases. This indicates that PMMA was generated from the initiating site locating at the outer most surface of the PPMI sheet, and the surface was completely covered with a grafted-PMMA segment. From TEM images, it is difficult to discuss whether PMMA is grafted from amorphous or crystalline part of PP due to the lack in resolution. However it is well-known that the surface of crystalline polymer has low crystallinity than internal phase. For instance, Nishino et al. has reported the surface structure of compression molded isotactic polypropylene film. ${ }^{26}$ They clearly showed the crystallinity of polypropylene was lower for the surface compared with the bulk by X-ray diffraction analysis. During ATRP, crystalline part of polypropylene sheet is not swellable by solvent and monomer at the mild condition. Therefore, we supposed ATRP of PMMA would take place selectively at amorphous phase near the surface.

The thickness of PMMA layer estimated by the TEM observation was plotted as a function of $M_{\mathrm{n}}$ of PMMA (Figure 7). ${ }^{27}$ The thicknesses of PMMA layer increased proportionally with $M_{\mathrm{n}}$ in all three PP-MI sheets, representing that the grafted PMMA chain was considered to be vertically grown due to the excluded volume effect of each graft chains. From the slopes of thickness- $M_{\mathrm{n}}$, PMMA-graft densities were estimated to be 0.19 chains $/ \mathrm{nm}^{2}$ at PP-MI sheet (SMI-1), 0.24 chains $/ \mathrm{nm}^{2}$ at PP-MI sheet (SMI-2) and 0.36 chains $/ \mathrm{nm}^{2}$ at PP-MI sheet (SMI-3), respectively. ${ }^{28}$ These graft densities are relatively high compared with the case of conventional chemical modification at the polyolefin surface, and are comparable to a so-called "polymer brush" which has been often fabricated on solid surfaces such as modified silicon substrate. ${ }^{9,10}$ It was also estimated that only the initiation sites located near the surfaces at a depth of 6-10 nm actually initiated for ATRP of the MMA on the supposition that they are homogeneously presented in whole PP-MI sheets.

The surface properties of PMMA-grafted sheets were evaluated by a water contact angle at $25^{\circ} \mathrm{C}$. Figure 8 shows dependence of the water contact angles of PMMA-grafted

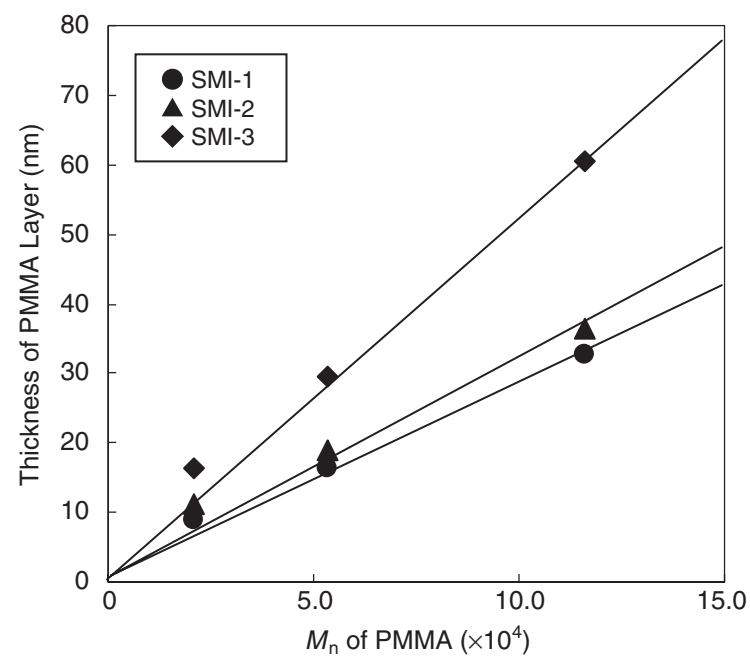

Figure 7. Thickness of PMMA layer plotted as a function of $M_{n}$. The comparison of the sheet grafted from different PP-MI: (a) SMI-1, (b) SMI-2 and (c) SMI-3.

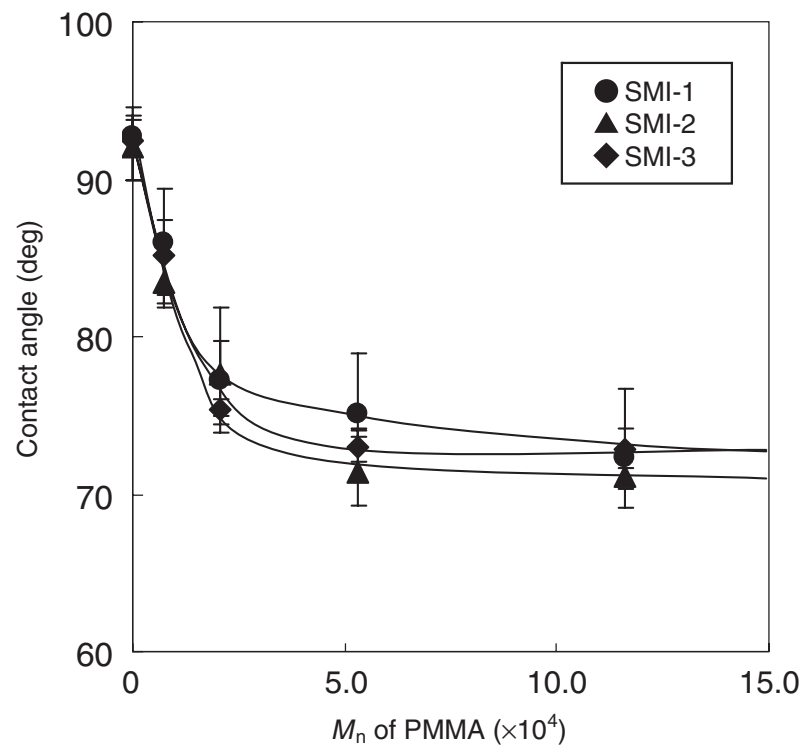

Figure 8. Water contact angles of PMMA-grafted PP sheets plotted as a function of $M_{\mathrm{n}}$. The comparison of the sheet grafted from different PP-MI: (a) SMI-1, (b) SMI-2 and (c) SMI-3.

sheet on $M_{\mathrm{n}}$ of grafting polymer. The contact angles of PP-MI with $\alpha$-bromoisobutyrate moiety were $92^{\circ}-93^{\circ}$, which were lower than that of non-modified polypropylene surface at $104^{\circ}$. Increasing $M_{\mathrm{n}}$ of the grafted PMMA, contact angle was gradually decreased from $93^{\circ}$ to $75^{\circ}$. When the $M_{\mathrm{n}}$ of PMMA brush was over $50000 \mathrm{~g} / \mathrm{mol}$, contact angle was leveled off at $70^{\circ}-75^{\circ}$, which are similar value to typical contact angle of bulk PMMA surface, indicating that the surface was absolutely covered with a PMMA layer.

\section{Dynamic Friction Tests on the Surface of PMMA-Grafted PP Sheet}

In general, it was difficult to coat and/or adhere polar 


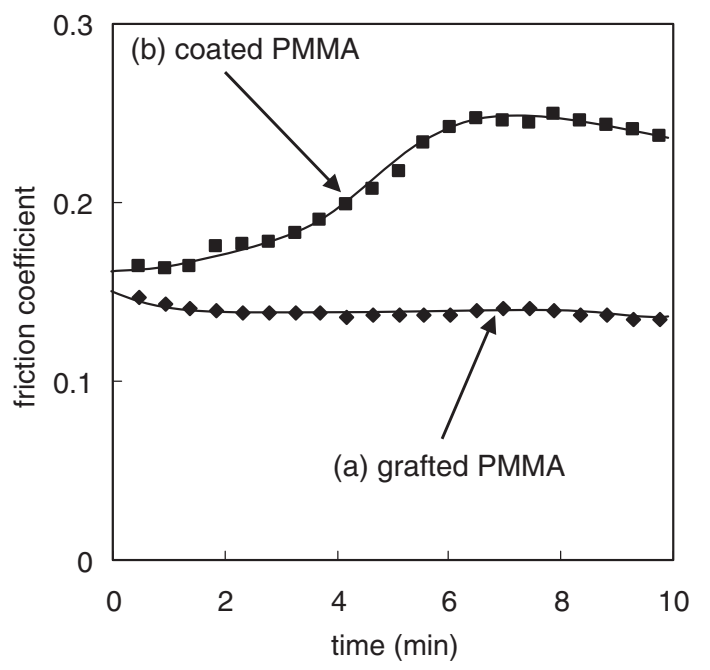

Figure 9. Friction coefficients of (a) PMMA-grafted sheet and (b) PMMAcoated sheet.

materials onto polyolefin because of the low polarity or inert reactivity of the simple methylene back-bone. Our methodology has the potential to immobilize various polar polymers on the outer most surface of PP. One of attractive feature of grafting polymer on the surface is low friction and wear resistance. ${ }^{29}$ In this work, the dynamic friction characteristics and the wear resistance of the grafted sheet on the basis of SMI-3 (the $M_{\mathrm{n}, \text { PMMA }}$ of $53700 \mathrm{~g} / \mathrm{mol}$ and the thickness of $29.4 \mathrm{~nm}$ ) were investigated by sliding a stainless ball on the sheets at a rate of $90 \mathrm{~mm} / \mathrm{min}$ under a normal load of $50 \mathrm{~g}$ $(0.49 \mathrm{~N})$. As comparison, PMMA-coated sheet, fixed the thickness of PMMA layer to $c a$. $30 \mathrm{~nm}$, prepared by spincoating of PMMA-free polymer $\left(M_{\mathrm{n}, \mathrm{PMMA}}\right.$ of $\left.53700 \mathrm{~g} / \mathrm{mol}\right)$ on the SMI-3 was also examined.

Figure 9 represents the time evolution of the friction coefficient during the continuous test for $600 \mathrm{~s}$ for the surface of PMMA-grafted sheet and PMMA-coated sheet. In the early stages of the friction test, the friction coefficient of PMMAgrafted sheet slightly decreased to 0.13 from 0.15 , but there was no further change during continuous friction, as shown in Figure 9a. On the other hand, PMMA-coated sheet gradually increased the friction coefficient to 0.23 from 0.16 (Figure $9 b$ ). The trace scratched by the sliding probe could be seen in the optical micrograph image of wear tracks after a 10 min friction test (Figure 10)

Topographic differences in the width and morphology of the scratched tracks were found between the grafted sheet and the coated sheet. PMMA-coated sheet showed a thick worn track as wide as $c a$. $100 \mu \mathrm{m}$ containing a lot of small PMMA debris. It is estimated from the worn track width that the sliding probe dented into the sheet at a depth of $3.6 \mu \mathrm{m}$. As the result, a sliding probe readily peeled PMMA-coated layer off because the PMMA was just adhere the PP surface without any chemical bonding for anchoring. In contrast, PMMA-grafted sheet showed no debris but a narrow groove line generated by the pressure of the probe. This result indicated that densely

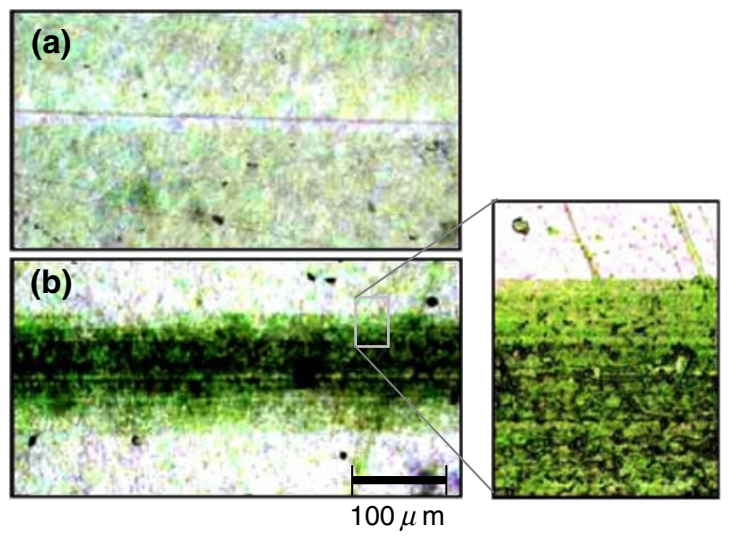

Figure 10. Optical micrograph images of wear track on the (a) PMMAgrafted sheet and (b) PMMA-coated sheet after sliding friction.

grafted structure of PMMA brush covalently anchored with the PP sheet surface improved wear resistance of surface coating layer. Accordingly, we suppose that immobilization of high density PMMA brush is effective in improvement of the physical properties of polyolefin surface having essentially poor adhesiveness to coating polar materials.

\section{Highly Wettable and Antibacterial Segment Grafted from PP Sheet}

Above-discussed modification technique based on surfaceATRP on the PP-MI sheet was probably expected to utilize widely for several methacrylate or acrylate monomers. From the industrial point of view, we tried to develop the high wettable and antibacterial surface of PP. MTAC was chosen as a methacrylate monomer for ATRP. Since this monomer is known to be highly hydrophilic nature which dissolved well in water and methanol, it was difficult to prepare poly-MTAC coated layer on hydrophobic PP surface by the simple casting method. In addition, a positively charged quaternary ammonium moiety of MTAC was expected to show antibacterial property. ${ }^{30,31}$

The surface-initiated ATRP of MTAC was carried out at $60{ }^{\circ} \mathrm{C}$ dipping a PP-MI sheet in MTAC/methanol solution in the presence of $\mathrm{CuBr} / \mathrm{PMDETA}$ and $\mathrm{EBiB}$. After $4.25 \mathrm{~h}$ at $60{ }^{\circ} \mathrm{C}$, MTAC conversion reached $98.5 \%$ (from GC analysis) to give a poly(methacryloxyethyltrimethyl ammonium chloride) (PMTAC)-grafted sheet. From the yield of PMTAC free polymer, the molecular weight was estimated to be as high as $187,600 \mathrm{~g} / \mathrm{mol}$.

XPS spectra revealed the formation of PMTAC layer by surface-initiated ATRP. The $\mathrm{N}_{1 \mathrm{~s}}$ peak was observed around at $400 \mathrm{eV}$, and the elemental component estimated from the area ratio was 4.5 atomic \% which value corresponded well with that of PTAC homopolymer of 4.6 atomic $\%$. This result indicated the formation of PMTAC-grafted layer on the surface of PP-MI sheet. The water contact angle of the resulting sheet was as low as $8^{\circ}$, due to the high wettable nature of the PMTAC segment. Surprisingly, the surface wettability has been kept even over a 6 month period. The immobilized polar 
Table III. Antibacterial test on the PMTAC-grafted PP sheet at $35^{\circ} \mathrm{C}$

\begin{tabular}{|c|c|c|c|}
\hline Bacteria & Incubation time & Sheet & $\begin{array}{l}\text { The number } \\
\text { of alive bacteria }\end{array}$ \\
\hline \multirow{2}{*}{$\begin{array}{c}\text { Escherichia } \\
\text { coli NBRC } \\
3972\end{array}$} & $\mathrm{Oh}$ & $P E^{a)}$ & $2.1 \times 10^{5}$ \\
\hline & $24 \mathrm{~h}$ & $\begin{array}{l}\text { PMTAC-grafted PP } \\
\text { PE }^{\text {a) }}\end{array}$ & $\begin{array}{c}30 \\
1.0 \times 10^{7}\end{array}$ \\
\hline \multirow{2}{*}{$\begin{array}{c}\text { Staphylococcus } \\
\text { aureussubsp } \\
\text { aureus NBRC } \\
12732\end{array}$} & $\mathrm{Oh}$ & $P E^{a)}$ & $2.2 \times 10^{5}$ \\
\hline & $24 \mathrm{~h}$ & $\begin{array}{l}\text { PMTAC-grafted PP } \\
\text { PE }^{a)}\end{array}$ & $\begin{array}{c}<10 \\
1.2 \times 10^{6}\end{array}$ \\
\hline
\end{tabular}

a) Non-modified polyethylene press sheet.

segment onto PP sheet maintained high wettability for a long time, suggesting a distinctive character of the grafted sheet not to be able to achieved the modification with small polar molecules. ${ }^{6,7}$

The antibacterial property of the resulting sheet was tested versus Escherichia coli NBRC 3972 and Staphylococcus aureussubsp aureus NBRC 12732. Table III showed the number of bacteria just after inoculating onto the sheet and after incubating for $24 \mathrm{~h}$ at $35^{\circ} \mathrm{C}$. The polyethylene sheet without any modifications was also used as a control sample. The non-modified sheet propagated both of the bacterias, 48 times for Escherichia coli and about 5 times for Staphylococcus aureus after incubation. On the other hand, PMTACgrafted sheet was almost rid of both of the bacteria after incubation. Accordingly, the introduction of a high-density cationic segment effectively invested high antibacterial property to the PP surface.

\section{CONCLUSIONS}

We have described the surface-initiated ATRP of MMA on the surface of the molded sheet based on the structurally welldefined polypropylene-macroinitiator. It has clearly been revealed that a high graft density polymer brush was formed as a thin layer on the surface of the PP, and the thickness of the layer was controlled well accompanying with the amount of initiation sites and the graft density. Dynamic friction tests showed that PMMA formed a stable layer because of the covalent bonding with the PP back-bone vis-a-vis PMMAcoated on the PP sheet. Furthermore, the formation of highly wettable PMTAC on the PP sheet drastically modified its wettability with no visual change, and also showed the high antibacterial properties. Therefore, polyolefin modifications through grafting-from methods described in this paper can be applied to variety of polyolefin moldings, such as films, sheets, nonwoven fabrics and injection-molded products.

Received: February 10, 2009 Accepted: April 1, 2009 Published: May 20, 2009

\section{REFERENCES}

1. W. Kaminsky, Macromol. Chem. Phys., 209, 459 (2008).

2. J. R. Rasmussen, E. R. Stedronsky, and G. M. Whitesides, J. Am. Chem. Soc., 99, 4736 (1977).

3. S. R. Holmes-Farley, R. H. Reamey, T. J. McCarthy, J. Deutch, and G. M. Whitesides, Langmuir, 1, 725 (1985).

4. S. R. Holmes-Farley and G. M. Whitesides, Langmuir, 3, 62 (1987).

5. J. Yamauchi, A. Yamaoka, K. Ikemoto, and T. Matsui, Bull. Chem. Soc. Jpn., 64, 1173 (1991).

6. T. Moro, Y. Takatori, K. Ishihara, T. Kanno, and Y. Takigawa, Nat. Mater., 2, 829 (2004).

7. S. Guimond and M. R. Wertheimer, J. Appl. Polym. Sci., 94, 1291 (2004).

8. T. Ogawa, S. Uematsu, and M. Gejyo, Koubunshi Ronbunshu, 65, 67 (2008).

9. "Polymer Brushes: Synthesis, Characterization, Applications," R. C. Advincula, W. J. Brittain, K. C. Caster, and J. Ruhe, Ed., Wiley VCH, Weinheim, 2004.

10. Y. Tsujii, K. Ohno, S. Yamamoto, A. Goto, and T. Fukuda, Adv. Polym. Sci., 197, 1 (2006).

11. S. M. Desai, S. S. Solanky, A. B. Mandale, K. Rathore, and R. P. Singh, Polymer, 44, 7645 (2003).

12. K. Yamamoto, Y. Miwa, H. Tanaka, and M. Sakaguchi, J. Polym. Sci., Part A: Polym. Chem., 40, 3350 (2002).

13. K. Yamamoto, H. Tanaka, M. Sakaguchi, and S. Shimada, Polymer, 44, 7661 (2003).

14. T. Matsugi, S. Kojoh, N. Kawahara, S. Matsuo, H. Kaneko, and N. Kashiwa, J. Polym. Sci., Part A: Polym. Chem., 41, 3965 (2003).

15. N. Kawahara, J. Saito, S. Matsuo, H. Kaneko, T. Matsugi, and N. Kashiwa, Adv. Polym. Sci., 217, 79 (2008).

16. Y. Inoue, T. Matsugi, N. Kashiwa, and K. Matyjaszewski, Macromolecules, 37, 3651 (2004).

17. H. Kaneko, S. Matsuo, N. Kawahara, J. Saito, T. Matsugi, and N. Kashiwa, Macromol. Symp., 260, 9 (2007).

18. J. Imuta, Y. Toda, and N. Kashiwa, Chem. Lett., 30, 710 (2001).

19. J. Imuta, Y. Toda, and N. Kashiwa, J. Am. Chem. Soc., 124, 1176 (2002).

20. R. Matsuno, K. Yamamoto, H. Otuska, and A. Takahara, Macromolecules, 37, 2203 (2004).

21. T. von Werne and T. E. Patten, J. Am. Chem. Soc., 121, 7409 (1999).

22. M. Husseman, E. E. Malmstrom, M. McNamura, M. Mate, D. Mecerreyes, D. G. Benoit, J. L. Hedrick, P. Mansky, E. Huang, T. P. Russell, and C. J. Hawker, Macromolecules, 32, 1424 (1999).

23. J. Pyun, S. Jia, T. Kowalewski, G. D. Patterson, and K. Matyjaszewski, Macromolecules, 36, 5094 (2003).

24. ${ }^{1} \mathrm{H}$ NMR signal intensity of methylene proton assigned to a terminal ethyloxycarbonyl moiety of PMMA free polymer described in Entry 4 in Table II was too weak to estimate molecular weight $\left(M_{\mathrm{n}, \mathrm{NMR}}\right)$.

25. J. F. Watts, S. R. Leadley, J. E. Castle, and C. J. Blomfield, Langmuir, 16, 2292 (2000).

26. T. Nishino, T. Matsumoto, and K. Nakamae, Polym. Eng. Sci., 40, 336 (2000).

27. The graft densities were estimated as the bulk density of grafted PMMA was $1.13 \mathrm{~g} / \mathrm{cm}^{3}$.

28. The thicknesses of PMMA layer on the sheet of Entry 1 in Table II, in which $M_{\mathrm{n}}$ of PMMA free polymer was $7200 \mathrm{~g} / \mathrm{mol}$, were not determined because PMMA layer was not observed clearly by TEM image.

29. H. Sakata, M. Kobayashi, H. Otsuka, and A. Takahara, Polym. J., 37, 767 (2005)

30. E. F. Panarin, M. V. Solovskii, N. A. Zaikina, and G. E. Afinogenov, Makromol. Chem. Suppl., 9, 25 (1985).

31. K. Katchalsky, Biophys. J., 4, 9 (1964). 